\title{
Changing priorities in residential medical and social services
}

\author{
David Greaves Centre for Philosophy and Health Care, University of Wales, Swansea
}

\begin{abstract}
During the past thirty years a high proportion of all long stay hospital beds have been closed. The responsibility for those who would have occupied those beds previously has to a large extent been transferred from health to social services departments, or to family, voluntary and private care. The overall effect has been to prioritise acute medical care, and to expose the public provision and funding of long term residential care, whether medical or social, to the direct determination of political and economic forces. These policy changes have been introduced under the banner of community care, but are dependent on complex concepts which are morally contentious and often obscure. The purpose of this paper is to analyse these processes as a prerequisite to devising better policies in future.
\end{abstract}

\section{Introduction}

Since the 1960 s a large proportion of all long stay hospital beds have been closed, ${ }^{1}$ the majority having been for the elderly, the mentally ill and the mentally handicapped (presently described as people with learning disabilities or difficulties). The rationale for the alternatives for those who would have occupied those beds previously, which are provided under the policy of community care, is much less clear than before in both theory and practice. The responsibility has to a large extent been transferred from health to social services departments or to family, voluntary and private provision, and the continuing role of medical services is contentious and uncertain. The purpose of this paper is to examine the implications of these major changes from conceptual and moral perspectives, particularly as they relate to questions of prioritisation.

\section{Historical background}

The foundations of the modern welfare state, as expressed for example in the Beveridge Report, ${ }^{2}$ envisaged medical and personal social services being

\section{Key words}

Community care; long term care; health care rationing. financed and provided by the state as a seamless whole, so that those in medical and social need would be ensured of care from "the cradle to the grave". Yet for those requiring long term residential care there was seen from the beginning to be what might be called a "natural faultline" between medical care and social care. Whereas the NHS was established on the principle that all in medical need, including those requiring long stay hospital care, would receive services free at the point of delivery, those in long stay residential and nursing homes were expected to contribute to the cost of their care in cases where they could afford to do so. It was not the intention though that anyone requiring long term residential social care should be excluded, only that they should be means-tested. The continuity of provision between those with medical and social needs was also emphasised by the position of the Medical Officer of Health, whose role within the local authority, when combined with that of Chief Welfare Officer, covered the overall planning and management of residential and nursing homes. This then was the basis on which long term residential care was provided from 1948 to 1970 , with the division between medical and social care being mainly restricted to financial matters.

However, by 1970 major changes were to challenge this position. First, all the functions within the local authorities which had a social element but had previously been fragmented were united within new unified social services departments, so that the Medical Officer of Health no longer had direct responsibility for residential and nursing homes. ${ }^{3}$ Thus what had been categorised as a public health function became re-categorised as a social one.

Second, at about the same time all health and social service provision came under political scrutiny, because the total cost of the services was rising, and this led to serious questioning of the original economic assumptions and administrative arrangements that had been put in place in 1948. A transition was occurring from the early postwar period of the welfare state, during which the nature of service provision was largely stable and taken for granted, with economic and administrative considerations being seen as secondary matters, to the more 
recent period where there have been substantial service re-organisations, in which economics and a new managerialism have taken precedence. During this later phase, from around 1970 to the present, the overriding imperative has been a concern with how to limit rising public costs.

A third and related issue was that a number of factors combined to produce an increased consciousness about these matters amongst the public. Most notable was the rising proportion of older people in the population, greater public scepticism as to the disinterestedness of the professions (including medicine), the rebellion of women against confinement to unpaid domestic and other roles in the economy, and technical advances in medical knowledge and practice.

Finally the policy of running down long stay hospitals and substituting community care, which was first proposed officially in relation to mental illness by the Royal Commission on Law Relating to Mental Illness and Mental Deficiency in 1957, has been transformed into a general ideological commitment to "Care in the Community", which has continued to gain ground practically and politically ever since. However, the different groups involved, principally the elderly, the mentally ill and people with learning difficulties have been affected in somewhat different ways (as will be discussed more fully later), and in the past few years the policy has met with some resistance.

The importance of these changes for this analysis is the way in which the concepts "medical" and "social" have been interpreted in relation to them, resulting in a new pattern of residential care which is markedly different from that which existed before.

\section{Two models of residential care services}

The traditional model for the provision of residential medical and social services instituted in 1948 embodied the following assumptions:

(1) Medical need is determined professionally by reference to absolute and factual scientific and technical criteria; social need is determined by a social and political process which is strongly influenced by professionals in the same way as with medical need.

(2) Residential medical services should be provided and funded by the state for all those in need of them; residential social services should be provided or made available by the state for all those in need of them, with funding to be determined by means testing, so dividing it into two elements according to the ability of individuals to pay - state-funded, and privately and voluntarily funded.

Until about 1970 residential services were, by and large, operated on the basis of this model. The difference in the way in which medical and social need

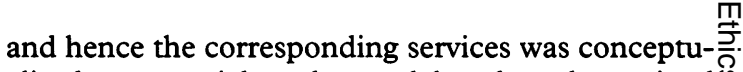
alised was crucial to the model and so determined? the way in which changes were to occur subse- $\overrightarrow{\vec{c}}$ quently.

As medical services came under pressure the $\frac{\text { 응 }}{0}$ typical reaction (largely shared by the health care $\frac{\bar{c}}{\mathrm{~s}}$ professions and the public) was to reassert the $\vec{\nabla}$ original principles of the NHS relating to medical $\bigcirc$ need, and to express regret that the ideals theye embodied might no longer be affordable. Thus if $\vec{\circ}$ reductions in services had to be made they were $\overrightarrow{-}$ usually seen as appropriately directed at those areas $\omega$ not central to medicine, for example, dentistry and infertility services, or described in terms of the unfortunate necessity for resource allocation. The $\mathrm{N}_{\mathrm{W}}^{\mathrm{N}}$ thrust of these responses is to indicate that in theiv former case the conditions involved do not "really" $\forall$ give rise to medical needs, and in the latter thato although there may be a medical need it is of low priority. What is not called into question is that $>$ medical needs can be defined separately from social . needs and that the relevant medical services should $\vec{\theta}$ ideally be funded by the state.

In contrast the concept of social need and its relationship with the provision of residential social services has traditionally been seen in a different way. The definition of social need has not been regarded as the exclusive preserve of a single professional group (having originally been seen as princi- $\stackrel{\AA}{\circ}$ pally within the province of medicine but more $\overrightarrow{\vec{B}}$ recently that of social work) or indeed as solely a 3 professional matter at all, because fundamentally it involves a social rather than a technical process. Thus the different status of "social" as opposed to "medical" needs raises doubts about who should $\Phi$ define the need for residential social care, and the extent of the state's responsibility for funding it. Hence when questions began to be posed about the $\frac{O}{3}$ provision of residential social services they arose against a background of less fixed ideas about what $?$ should be provided when compared with medical $\$$ services, and did not presuppose any set level for the proportion of funding that the state should provide. N So debates about such funding are not characterised $N$ by considerations of the precise limits of social need or service provision, but are conducted in terms of ${ }^{\mathcal{C}}$ political negotiations regarding variations in funding rather than of resource allocation, because they are not seen as being measured against a fixed amount of need which ideally should be funded.

These differences in understanding find expres- $-\frac{0}{0}$ sion in the different provision and development of government policy for medical and social care since $\frac{}{\mathrm{P}}$ 1970. Long term residential medical care in hospital $\varrho$ has become progressively redefined as not deriving? from "real" medical needs, or only doubtfully so and thus the state has no obligation to provide or fund? it as of right. Two factors have been instrumentalō. in enabling this conceptual shift and ensuring its? conversion into changes in policy. The first is that 
collectively the health care professions tend to regard long term care as a poor relation within medicine as a whole, and this is confirmed by the use of the term "cinderella services" applied in relation to geriatrics and mental health services. So when pressed these professions have not mounted any powerful defence of long stay medical services, especially when they are in competition with acute services. The second is the widespread ideological consensus that has developed over recent years and already been referred to, in favour of a policy of community care in preference to long term residential medical care for patients of all specialties. Not surprisingly the outcome has been a sharp reduction in the number of long stay hospital beds provided.

In recent years the provision of long term residential places labelled social, and state funding for them, has shown an increase at the same time as long term medical beds and funding have decreased. However, the pattern has varied in relation to different care groups, mainly because of the way that the policy of community care has developed. For some former long stay patients, most notably the mentally handicapped, the change in their designation to people with learning disabilities or difficulties has been accompanied by proposals that ordinary domestic houses rather than residential places of any description are appropriate for most of them. To a lesser degree this is also what has happened with respect to long stay mentally ill patients; but the elderly have tended to be viewed differently, still being seen as having special needs requiring long term residential provision, though in homes rather than hospitals. Consequently it is mainly for this group that there has been a large increase in the number of residential places, although the development of these services has arisen in a haphazard, rather than a carefully planned, fashion and came about as follows.

During the 1980s the number of local authority places in residential homes for the elderly were reduced, but were more than compensated for by places in private and voluntary homes, with the majority of clients being paid for through the social security system. ${ }^{4}$ As far as funding was concerned this represented a switch from one public purse, administered by social services departments, to another, administered by social security offices. What is of particular interest for this analysis is that in determining who was entitled to social security, as opposed to social services, funding there was little if any reference to need for social care, the main criterion being ability to pay. The decision as to who was entitled to social security funding was, therefore, principally based on a political and economic calculation which, when it worked out in practice to be far more generous then was originally intended, was equally open to being restricted by direct political intervention, as has tended to occur since the implementation of the community care provisions of the 1990 NHS and Community Care Act in 1993. Thus the professional element in determining the need for social care and its use as a criterion for entitlement to both provision and funding has become increasingly marginalised and this lack of reference to measurable standards reveals the weakness of social need as a necessary feature in determining levels of care and public funding. This is not to suggest that professional definitions of social need should take automatic priority, but rather that they should always be given serious consideration.

The combined effect of these changes has been that long stay residential medical care has been sharply reduced by re-defining the main care groups involved as either not in need of special residential provision at all, or in need of social rather than medical provision. This has resulted in a different model of residential care provision and some important conceptual differences can be noted when this is compared with the original model:

(1) Medical need continues to be determined professionally by reference to absolute scientific and technical criteria, but this is no longer seen as appropriate in relation to long term residential medical care, which has therefore been reduced and in theory could be eliminated altogether. By implication acute medical provision has been prioritised at the same time.

(2) Determining how to provide social care has tended to become more a political than a professional process, one result being that the public funding of long term residential social provision is more readily varied then previously.

\section{New directions}

For those who find the contemporary model which prioritises acute medical care over long term residential care (whether medical or social) troubling, it is necessary to address the issues not only at a moral and political level, but also conceptually. It is important to address these issues conceptually in order both to lend substance to criticisms of that model, and to provide a sound basis from which to develop new and better directions.

The contemporary model of how long term residential care should be provided rests on one particular but widely-held understanding of medical and social knowledge which is nevertheless rarely made explicit in debates about health and social policy. It is well expressed by Wulff ${ }^{5}$ who makes the distinction between what he sees as scientific and humanistic medicine, by which he divides disease into those which are "traditional", for example. acute appendicitis, and those which are "modern", for example hemiplegia giving rise to aphasia in an old person. $\mathrm{He}$ considers that scientific knowledge is only involved in the former and so is making a positivist differentiation between medicine which is value-free (mainly acute conditions) and that which is value-laden (mainly 
chronic conditions). Such a position may then lead to the acute scientific part of medicine being seen as necessarily defined by doctors and representing the central and unequivocal core of health care which there is an imperative for the state to provide. By contrast the chronic humanistic part of medicine has an uncertain status, being seen as more appropriately categorised as social than medical, so that state involvement in the care of these conditions is properly determined according to prevailing political and economic circumstances. What follows is that the faultine between concepts of what is medical and social still exists, but has been re-located.

Two aspects of this approach to medical knowledge are unsatisfactory and require revision; first the assumption of an absolute separation between scientific and humanistic medical knowledge; and second that scientific medical knowledge is factual and thus to be defined by doctors, whereas humanistic medical knowledge is value-laden and so part of social knowledge to be determined politically. A different view, which would dispense with both of these features, would involve a new understanding of the relationship between scientific medical knowledge and social knowledge as not clearly separable, but rather part of a continuum permeated throughout by both facts and values. There would not then be an exclusive scientific medical sphere to be defined by doctors, nor an exclusive social sphere to be defined politically, but instead the whole of the new combined medical and social realm would be open to a different admixture of professional and political determination. It is not that the former boundaries of medical and social categories would disappear altogether, but they would be less sharp. Thus what is considered medical and so also medical need would acquire a less exact definition, and conversely that considered social and social need would gain a more definite outline.

The present purpose is not to explore the detail of how this might be accomplished, but rather to draw attention to the changes that it would entail in the way in which the state determined its duties in the provision and funding of residential medical and social care. The three main elements of the two models, acute medical care, long term residential medical care, and long term residential social care would all need to be considered on a more equal footing. Acute medical care would lose its previous status, common to both models, whereby it was almost exclusively defined by doctors and received virtually automatic priority, whilst all long term residential care would also change its status but in the opposite direction, being less open to direct political determination and becoming included in a wider debate about prioritisation across the whole of medical and social services.

\section{Conclusion}

Although this analysis has mainly been concerned with the provision of residential care, it is of relevance to all aspects of the relationship betwee $\overrightarrow{5}$. medical and social services. It has shown that policfy. changes do not result from the unmediated inter $\overrightarrow{\vec{*}}$ play of professional and political debates, but are dependent on complex concepts which are morallf contentious and which are not usually madeexplicit. The processes involved are thus obscured and in this example the social inequality arising from continuing to favour acute medical care carf all too readily be ignored or even go unnoticed $\vec{D}$ Uncovering these issues is then an important pre $=$ requisite in devising better policies for the future $\mathcal{O}^{-}$

This new understanding would also allow the ideological debate about community care to be dise entangled from the issue of public funding of services. The contemporary model is politically convenient in that it permits community care to be equated with social care or self care which is ideally seen as non-residential, and so appears to hold out the prospect of a service which is more acceptables and cheaper than traditional institutional careㅡ. However, by challenging this model, what would count as appropriate care would no longer have to be argued for as a cost-cutting alternative to medical care, so how community care should beo provided and funded could be viewed more openlys and with greater dispassion. The question being raised would then be how best to categorise, meeg and fund different types of need without being tied? to unquestioned historical assumptions: this would $\vec{b}$ allow the place of long term residential care and $\mathrm{B}$ other potentially costly care options to be re-con sidered on their merits, without the question of whether they are considered medical or social being of primary importance.

\section{Acknowledgements}

I wish to thank Richard Bryden, Elizabeth James and the anonymous reviewers for their comments on this paper.

David Greaves, $M B, M A, M L i t t, P h D$, is Lecturer in Philosophy and Health Care, the Centre for Philosophy and Health Care, University of Wales, Swanseas Wales.

\section{References and notes}

1 Since the 1960 s the total number of hospital beds in England for the combined specialties of geriatrics, psyo chiatry and mental handicap or learning disability hasp been reduced to less than half. Health and Personal Socia? Services Statistics for England [published annually] London: HMSO.

2 Beveridge Report. Social Insurance and Allied Services London: HMS0, 1942.

3 The Seebohm Committee on Personal Social Services, which reported in 1968, was followed by the Socias Services Act of 1970, which established unified Social Services Departments within local government. 
4 Between 1984 and 1994 the number of elderly residents in local authority homes fell by nearly a half, whilst those in voluntary and private homes more than doubled. Health and Personal Social Services Statistics for England [published annually]. London: HMSO.
5 Wulff HR. Function and value of medical knowledge in modern diseases. In: Ten Have HAMJ, Kimsma GJK, Spicker SF, eds. The growth of medical knowledge. Dordrecht: Kluwer Academic Publishers, 1990: 75-86.

\section{News and notes}

\section{Seminar on Alternatives to Animal Use in Education, Research and Testing}

On June 28, 1997, Indiana University's Poynter Center for the Study of Ethics and American Institutions will sponsor a one-day seminar on Alternatives to Animal Use in Education, Research, and Testing. The seminar will provide participants with information about the history of the search for alternatives, current developments, bibliographic resources, and an opportunity for discussion of alternatives and related issues. The seminar will be led by Dr R Lee Zasloff, Associate Director of the University of California Center for
Animal Alternatives in Davis, California. Researchers, educators, IACUC members, students, and other individuals interested in issues of animal use are welcome to attend. The seminar fee is $\$ 50$, which includes all materials and lunch. Space is limited.

For more information: Kenneth D Pimple, $\mathrm{PhD}$, Poynter Center, Indiana University, 410 North Park Avenue, Bloomington IN 47405; (812) 855-0261; fax: 855-3315; pimple@indiana.edu;http://www.indiana. edu/ poynter/index.html.

\section{News and notes}

\section{Health for the Millions}

The July/August 1996 issue of Health for the Millions, published in New Delhi, India, was entirely devoted to medical ethics. It contains articles on ethics and medical education, ethical issues in medical science and human rights violations and medical ethics. The magazine is obtainable from: Health for the Millions Trust, c/o VHAL, Tong Swasthy Bhawan, 40 Institutional Area, Behind Qutab Hotel, New Delhi - 110016, India.

\section{News and notes}

\section{AIDS targeted information}

CAB INTERNATIONAL ("CABI"), Wallingford, Oxon OX10 8DE, UK has announced that it will publish AIDS Targeted Information ("ATIN"), formerly published by Libex Inc, 1316 East 10th Street, Brooklyn, New York, NY1 1230, USA.

From 1 January 1997, ATIN will incorporate Current AIDS Literature, currently published by CABI, which will be discontinued. The new combined monthly HIV/AIDS abstract and reviews journal will assume the title of AIDS Targeted Information.

The editor and current owner of ATIN, Professor Russell E MacDonald, will be remaining as the US editor of the new journal, and will join Mrs Hilary Richardson, who will assume the editorship in the United Kingdom. Each month the new journal will begin with an in-depth editorial, followed by editorial reviews on epidemiology, clinical aspects, medical microbiology and social aspects, together with a comprehensive bibliographic listing in each category.
The price of AIDS Targeted Information (volume 11 ) in 1997 will be: member country $£ 220.00$, nonmember country $£ 275.00$ and the Americas US\$300.00.CAB INTERNATIONAL also publishes the AIDS Newsletter, the price of which is: member country $£ 92.00$, non-member country $£ 115.00$ and the Americas US $\$ 220.00$. A discounted package price is available for the two journals, please apply for details.

For further information contact: Claire Gilman, Product Manager, Human Health \& Animal Science, CAB INTERNATIONAL, Wallingford, Oxon OX10 8DE, UK, telephone +44 (0) 1491832111 , fax: +44 (0)1491826090,E-mail c.gilman@cabi.org

Pam Sherman, Market manager, North America, CAB INTERNATIONAL, 198 Madison Avenue, New York, NY 10016 USA, telephone +1 (212) 726 6490, fax: +1 (212) 686 7993, E-mail cabi-nao @cabi.org 